\title{
Craniofacial Morphology and Upper Airway Dimensions in Patients with Hypermobile Ehlers-Danlos Syndrome Compared to Healthy Controls
}

\author{
Liselotte Sonnesen ${ }^{1}$, Tessie Pawlik ${ }^{1}$, Eva Fejerskov Lauridsen² \\ ${ }^{1}$ Section for Orthodontics, Department of Odontology, Faculty of Health and Medical Sciences, University of Copenhagen, \\ Denmark. \\ ${ }^{2}$ Resource Center for Rare Oral Diseases, Copenhagen University Hospital, Rigshospitalet, Copenhagen, Denmark.
}

Corresponding Author:

Liselotte Sonnesen

Section of Orthodontics, Department of Odontology

Faculty of Health and Medical Sciences, University of Copenhagen

20 Nørre Alle, DK-2200 Copenhagen

Denmark

Phone: 004535326670

E-mail: alson@sund.ku.dk

\begin{abstract}
Objectives: The aims of the present case-control study were to compare craniofacial morphology, airway minimum crosssectional area and airway volume between patients with hypermobile Ehlers-Danlos syndrome and healthy controls.

Material and Methods: The sample comprised 18 hypermobile Ehlers-Danlos syndrome (hEDS) patients (16 females, 2 males, mean age 34.1 [SD 10.35] years), clinically diagnosed and genetically tested in order to exclude other types of EDS, and 16 controls (14 females, 2 males, mean age 37.9 [SD 10.87] years) with neutral occlusion and normal craniofacial morphology. Craniofacial morphology was assessed on lateral cephalograms. Minimum cross-sectional area and upper airway volume were assessed on cone-beam computed tomography and analysed by standard and well-validated methods. Differences were tested by logistic regression analysis adjusted for age, gender and body mass index (BMI).

Results: No significant differences in craniofacial morphology were found between hEDS patients and controls. Airway minimum cross-sectional area $(\mathrm{P}=0.019)$ and airway volume $(\mathrm{P}=0.044)$ were significantly smaller in hEDS patients compared to controls. When adjusted for age, gender and BMI no significant differences were found. However, minimum cross-sectional area was almost significant $(\mathrm{P}=0.077)$.

Conclusions: The craniofacial morphology and airway dimensions of hypermobile Ehlers-Danlos syndrome patients were comparable to controls, with a tendency towards a smaller minimum cross-sectional area in the hypermobile Ehlers-Danlos syndrome group. The results may prove valuable for understanding the effect of hypermobile Ehlers-Danlos syndrome on craniofacial morphology and the upper airways.
\end{abstract}

Keywords: adult; cone-beam computed tomography; face; pharynx; syndrome.

Accepted for publication: 25 June 2021

To cite this article:

Sonnesen L, Pawlik T, Fejerskov Lauridsen E.

Craniofacial Morphology and Upper Airway Dimensions in Patients with Hypermobile Ehlers-Danlos Syndrome Compared to Healthy Controls

J Oral Maxillofac Res 2021;12(2):e5

URL: http://www.ejomr.org/JOMR/archives/2021/2/e5/v12n2e5.pdf

doi: $10.5037 /$ jomr.2021.12205 


\section{INTRODUCTION}

The Ehlers-Danlos syndrome (EDS) is a group of inherited connective tissue disorders caused by abnormalities in the structure, production and/or processing of collagen [1]. These disorders show considerable clinical and genetic heterogeneity and affect multiple organ systems. Joint hypermobility, dermal extensibility and cutaneous scarring compose the classical triad of the disorder [2]. Due to the vast genetic heterogeneity and phenotypic variability and the clinical overlap between EDS subtypes, but also with other heritable connective tissue disorders, the definite diagnosis of all EDS subtypes, except for the hypermobile type, relies on molecular confirmation with identification of causative genetic variants [1]. The estimated prevalence of EDS is $1 / 5,000$, and the hypermobile EDS (hEDS) subtype is the most frequent [3]. hEDS, which is considered the least severe subtype of EDS, can only be diagnosed clinically and relies on three criteria outlined by the 2017 classification [1,4]. However, genetic testing is used in order to exclude other types of EDS [1]].

The upper airway consists of the external nose, internal nose or nasal cavity, paranasal sinuses, the oral cavity and the pharynx []]. The pharynx is subdivided into the nasopharynx, oropharynx and laryngopharynx and is part of the digestive system and conducting zone of the respiratory system $[\underline{6}, \underline{7}]$. The walls of the pharynx consist of connective tissue and skeletal musculature $[\underline{6}, \underline{7}]$ enclosed by bony structures []. Upper airway volume and minimum crosssectional area have not previously been investigated in EDS, but studies have found that obstructive sleep apnea (OSA) is significantly more frequent in EDS compared to controls [9-11]. The small minimum cross-sectional area has been found to be the most relevant anatomical characteristic of the upper airway related to the pathogenesis of OSA [12].

The craniofacial morphology in EDS has seemingly only been reported in studies using clinical assessment or quantitative photographic analysis technique $[\underline{9}, \underline{10}]$. One study using photography found no significant differences in craniofacial morphology in EDS compared to controls [9] , whereas a clinical assessment showed that EDS had significant nasal septum deviation with internal valve collapse, high arched palatal vault, micrognathia, tongue scalloping and cross bite [10].

As EDS is a disorder that inflicts the connective tissue, it is reasonable to hypothesize that this may lead to changes in the soft tissue, e.g. upper airway dimensions and/or skeletal morphology of the craniofacial complex in patients with EDS.

The aim of the present case-control study was to compare craniofacial morphology and upper airway dimensions between a group of hypermobile EhlersDanlos syndrome patients and a healthy control group.

\section{MATERIAL AND METHODS Subjects}

The patient group was extracted from a larger group of hEDS patients comprising part of another study $(\mathrm{n}=26)$, which was conducted between August $1^{\text {st }}$ and November 30 2017 [13]. Inclusion criterion was clinical hEDS diagnosed by a rheumatologist according to the Villefranche classification [14] and differentiated by a genetic test in order to exclude other types of EDS.

The genetic test was performed on all hEDS patients and carried out from a saliva sample mixed with residues from a mucosa scrape. The sample was tested for mutations in genes associated with other EDS subtypes: COL3A1, COL5A1, COL5A2, COL1A1, COL1A2, PLOD1 and CHST14 in preparation for confirming and excluding other EDS subtypes than hEDS [1]. Exclusion criteria: (a) incomplete lateral cephalogram or cone-beam computed tomography (CBCT) image and/or (b) compromised imagery of upper airways in three-dimension due to swallowing during execution (Figure 1).

Thus, the patient group included 18 patients with hEDS (16 females, 2 males, mean age 34.1 (SD $10.35)$ years). The mean body mass index (BMI) was 26.3 (SD 5.88).

The control group was selected from a larger group of healthy controls and comprised students and staff members at the Department of Odontology, University of Copenhagen $(n=39)$ [13]. Inclusion criteria:

- No known diseases or syndromes;

- Neutral craniofacial morphology (sagittal jaw relation: $2^{\circ}$ [SD $2.5^{\circ}$; vertical jaw relation: $25^{\circ}$

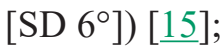

- Neutral occlusion;

- No history of orthodontic treatment.

Exclusion criteria (Figure 1):

- Incomplete lateral cephalogram or CBCT image;

- Compromised imagery of upper airways in threedimension due to swallowing during execution.

Thus, 16 individuals (14 females, 2 males, mean age 37.9 [SD 10.87] years) comprised the control group of the present study. The mean BMI was 23.9 (SD 3.52). When power analysis was performed under the assumption that the differences in craniofacial morphology and upper airway dimensions occur 


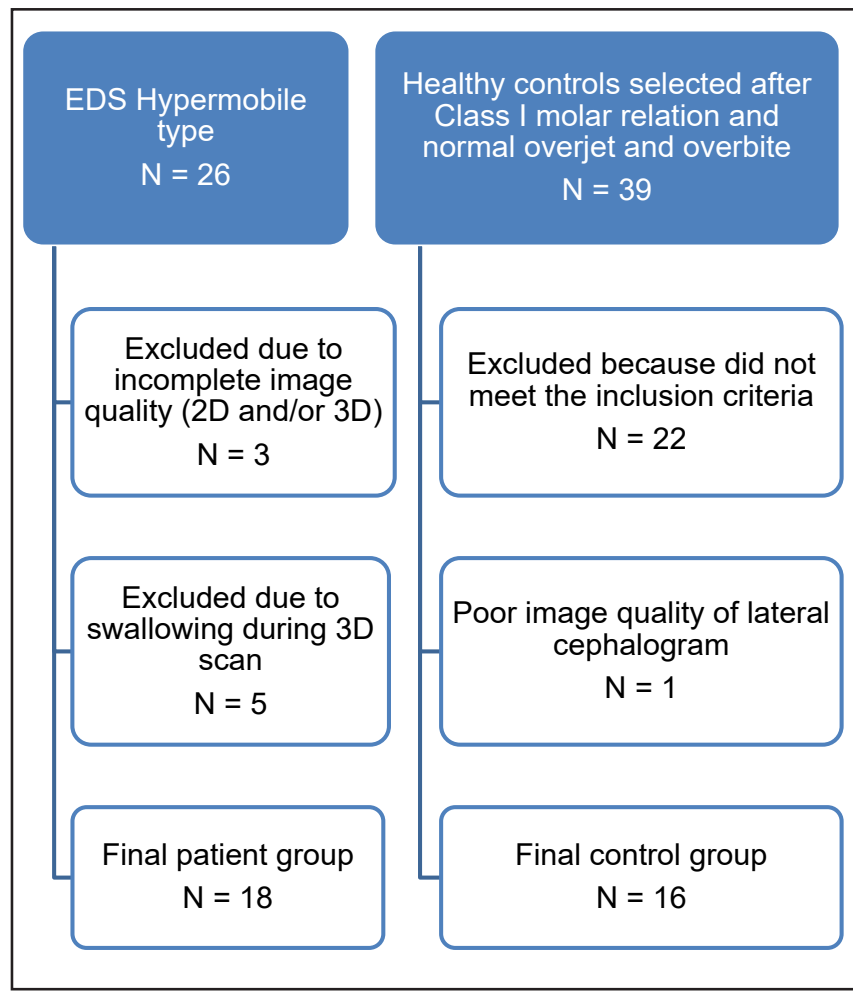

Figure 1. Flow chart.

in $50 \%$ in patients with EDS, at least 16 subjects in each group were required to have sufficient power $(80 \%)$ in order to identify statistically significant differences at the $5 \%$ level of significance. Thus, the sample size was considered sufficient in the present study.

The study followed the guidelines of the Declaration of Helsinki and was approved by the Danish National Committee on Health Research Ethics (Protocol H-17015290) and the Danish Data Protection Agency (SUND-2017-28).

\section{Methods}

Lateral cephalograms were obtained in order to assess the craniofacial morphology, and CBCT scans were recorded to assess the dimensions of the upper airway. All were taken at the Cephalometric Laboratory, Department of Odontology, University of Copenhagen. The radiographs and scans were taken after randomization in order to blind the observer to the health status of the individuals. The lateral cephalograms were obtained in a Promax (2D X-rayUnit - Planmeca OY; Helsinki, Finland, 2012) with a focus to sensor distance of $501 \mathrm{~mm}$, enlargement of $13 \%$ and resolution of 183 . The CBCT scans were obtained in a Promax (3D Max Sensorhead, sensor type 2520E - Planmeca Oy; Helsinki, 2012) with a focus to sensor distance of 632 and maximum field of view of $230 \times 260 \mathrm{~mm}$. All two-dimensional

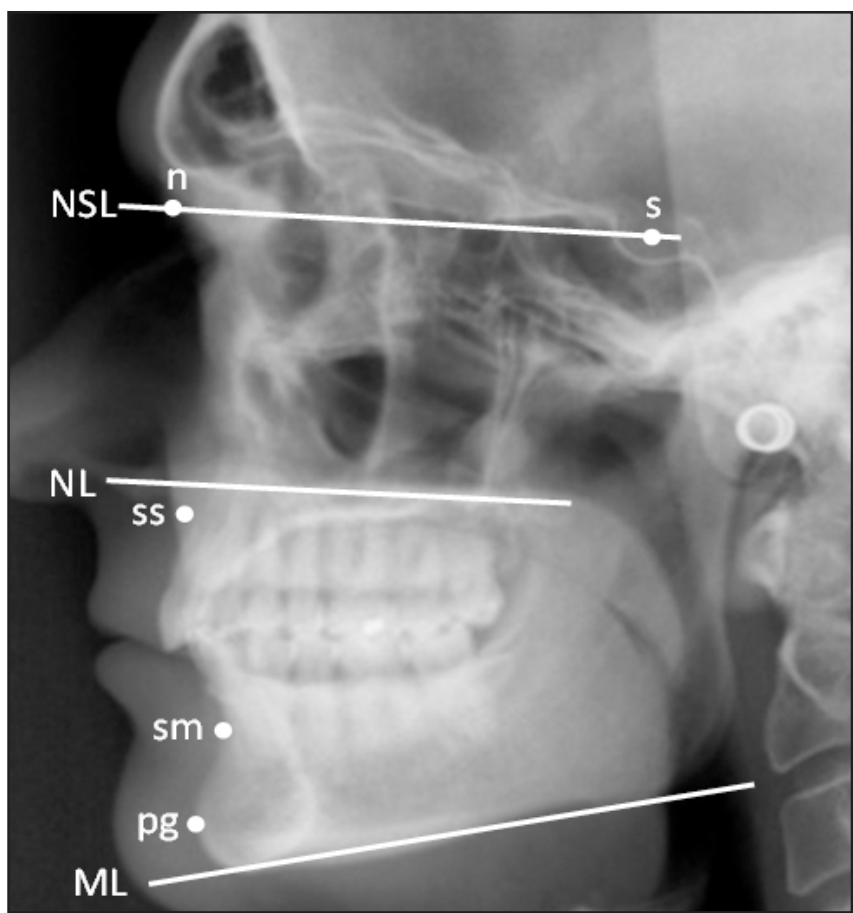

Figure 2. Illustration of points and lines for the craniofacial morphology variables (Björk [15]).

$\mathrm{s}=$ sella; $\mathrm{n}=$ nasion; $\mathrm{ss}=$ subspinale; $\mathrm{pg}=$ pogonion; $\mathrm{NSL}=$ nasionsella-line; $\mathrm{NL}=$ nasal-line; $\mathrm{ML}=$ mandibular-line.

Sagittal variables: sagittal jaw relation (ss-n-pg), maxillary prognathia (s-n-ss), mandibular prognathia (s-n-pg). Vertical variables: vertical jaw relation (NL/ML), maxillary inclination (NSL/NL), mandibular inclination (NSL/ML).

and three-dimensional images were taken in the natural head position as evaluated by mirror $[\underline{16}, \underline{17}]$.

For the analysis of the craniofacial morphology, variables in the sagittal and vertical dimensions were used [15]. The sagittal variables were: sagittal jaw relation (ss-n-pg), maxillary prognathia (s-n-ss) and mandibular prognathia (s-n-pg) (Figure 2). The vertical variables were: vertical jaw relation (NL/ $\mathrm{ML}$ ), maxillary inclination (NSL/NL) and mandibular inclination (NSL/ML) (Figure 2). The lateral cephalograms were digitized in Total Interactive Orthodontic Planning System version 4.4.0.0 (Tiops5; Copenhagen, Denmark).

The pharyngeal airway volume and the minimum cross-sectional area (Figure 3) were analysed by Romexis 3D imaging software (Planmeca OY; Helsinki, Finland, 2012) after importing the DICOM images into the program $[\underline{18}, \underline{19}]$. The upper airway margins were manually determined according to previously validated definitions and methods $[\underline{18}, \underline{19}]$. The upper airway margins were outlined in the midsagittal plane. The midsagittal plane was identified as the sagittal slice that includes the anterior nasal spine and incisive canal [18]. The superior border was the nasal floor in the level of the posterior nasal spine. The inferior border was the base of the epiglottis. 


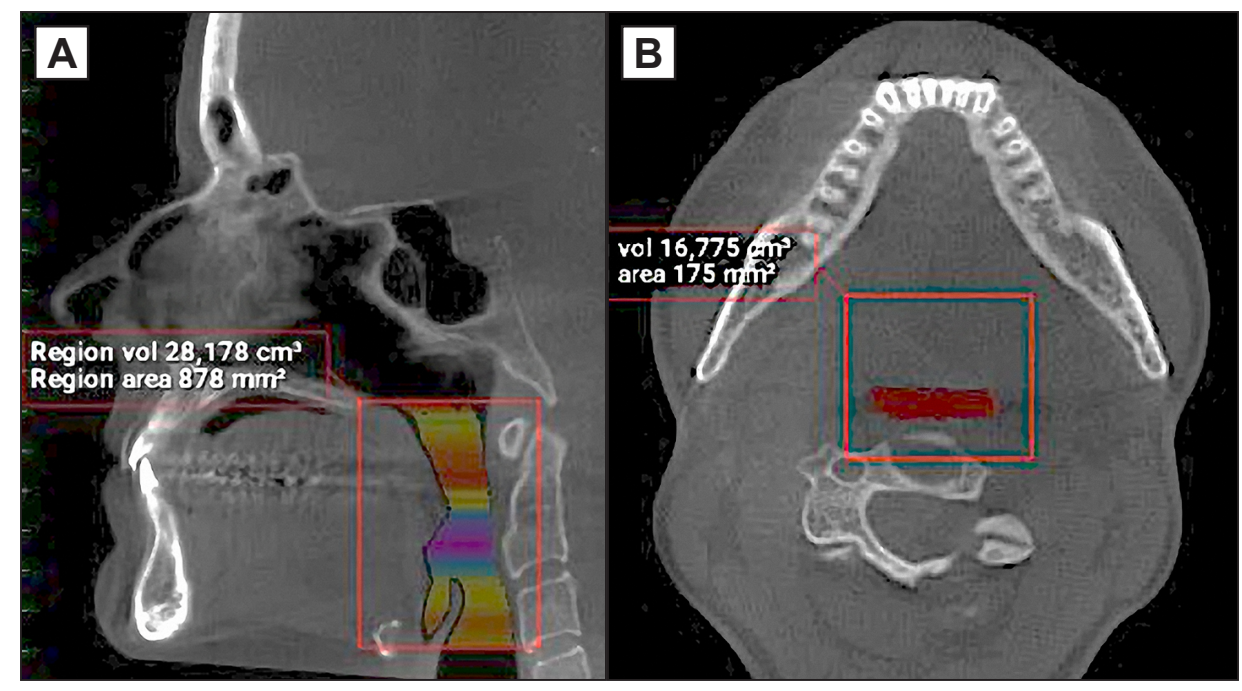

Figure 3. Illustration of the upper airway volume and cross-sectional area: $\mathrm{A}=$ sagittal; $\mathrm{B}=$ axial plane. Airways coloured by area: narrowest passages with the smallest area are highlighted in red.

In the axial plane, it was checked that the pharynx was included in its full extension from top to bottom according to the chosen superior and inferior margins $[\underline{18}, \underline{19}]$. Airway volume was then calculated in the program using the designated tool. Volume was measured in $\mathrm{cm}^{3}$. The minimum cross-sectional area was determined by scrolling from superior to inferior margin in the axial plane until the smallest measurement was encountered $[\underline{18}, \underline{19}]$. The minimum cross-sectional area was measured in $\mathrm{mm}^{2}$.

\section{Reliability}

To determine the intra-examiner reliability, a total of 25 randomly chosen lateral cephalograms and corresponding three-dimensional scans were analysed twice within 2 weeks. SPSS software version 26.0 (IBM Inc.; Chicago, Illinois, USA) was used for the data analysis. For the assessment of systematic error, a paired sampled t-test was performed. No systematic error was found. For the evaluation of measurement error and the reliability the Dahlberg formula [20] and the Houston's reliability coefficient [21] were used, respectively. The method error for the craniofacial morphology ranged between $0.003^{\circ}$ and $0.015^{\circ}$, for the upper airway volume $0.016 \mathrm{~cm}^{3}$ and minimum cross-sectional area $0.5 \mathrm{~mm}^{2}$. The reliability coefficient for both the craniofacial morphology and the upper airway dimensions was 1 .

\section{Statistical analysis}

Statistical Analysis Software (SAS) version 9.4 (Cary, N.C., USA) and IBM SPSS Statistics Version 26 (IBM Inc. Chicago, Illinois, USA) was used for the statistical analysis. Parametric data were expressed as mean and standard deviation (M [SD]) and the statistical significance level was defined at $\mathrm{P}<0.05$. The distribution of the data was assessed by QuantileQuantile plots (Q-Q-plots). The data was normally distributed. The difference in distribution of gender was assessed by Fisher's exact test. Age and BMI differences between the two groups were tested by an independent t-test. Differences in craniofacial morphology and airway dimensions between the two groups were investigated by logistic regression. The first analysis was univariate with each covariate as the explanatory variable and hEDS/control as the dependent variable. Model validation was performed using residuals and tests for goodness of fit. The second analysis was similar to the first, though adjusted for age, gender and BMI. The primary statistical analysis included logistic regression analysis modelling the probability for hEDS. Results were presented by odds ratios (OR) with 95\% confidence limits and the concordance statistic or $\mathrm{C}$-statistic/area under the curve.

\section{RESULTS}

There was no significant difference in gender, age or BMI distribution between the two groups (P-value $>0.05$ respectively).

Regarding the skeletal craniofacial morphology in the sagittal and vertical plane, no statistically significant differences were shown between the two groups (P-value $>0.05$ respectively, Table 1 and 2). Regarding the incisal relationship in terms of overjet and overbite, no statistically significant differences were found between the groups (P-value $>0.05$ respectively, Table 1 and 2). 
Table 1. Differences between the groups

\begin{tabular}{l|c|c|c|c|c|c}
\hline Marker & $\begin{array}{c}\text { Odds } \\
\text { ratio }\end{array}$ & $\begin{array}{c}\text { OR } \\
\text { lower CL }\end{array}$ & $\begin{array}{c}\text { OR } \\
\text { upper CL }\end{array}$ & P-value & AUC & $\begin{array}{c}\text { Mean difference } \\
\text { (control - hEDS) }\end{array}$ \\
\hline Airway dimensions & 0.85 & 0.72 & 1 & $0.044^{\mathrm{a}}$ & 0.7 & 3.8 \\
\hline Volume (cm $\left.{ }^{3}\right)$ & 0.99 & 0.97 & 1 & $0.019^{\mathrm{a}}$ & 0.75 & 67.1 \\
\hline Min. cross-sectional area $\left(\mathrm{mm}^{2}\right)$ & \multicolumn{7}{l}{} & \\
\hline Craniofacial morphology & 1.03 & 0.72 & 1.46 & 0.871 & 0.51 & -0.1 \\
\hline ss-n-pg (degrees) & 0.97 & 0.79 & 1.18 & 0.755 & 0.55 & 0.4 \\
\hline s-n-ss (degrees) & 0.97 & 0.8 & 1.17 & 0.717 & 0.52 & 0.5 \\
\hline s-n-pg (degrees) & 0.93 & 0.8 & 1.06 & 0.277 & 0.63 & 1.9 \\
\hline NL/ML (degrees) & 1.15 & 0.92 & 1.44 & 0.231 & 0.62 & -1.3 \\
\hline NSL/NL (degress) & 0.98 & 0.87 & 1.1 & 0.745 & 0.58 & 0.6 \\
\hline NSL/ML (degrees) & 1.31 & 0.69 & 2.51 & 0.409 & 0.55 & -0.3 \\
\hline Incisal relations & 1.09 & 0.62 & 1.92 & 0.764 & 0.57 & -0.1 \\
\hline Overjet (mm)
\end{tabular}

a Statistically significant at level $\mathrm{P}<0.05$ (Paired samples t-test).

$\mathrm{OR}=$ odds ratio; $\mathrm{CL}=$ confidence level; $\mathrm{AUC}=$ area under the curve; ss-n-pg = sagittal jaw relation; s-n-ss = maxillary prognathia; s-n-pg = mandibular prognathia; $\mathrm{NL} / \mathrm{ML}=$ vertical jaw relation; NSL/NL = maxillary inclination; NSL $/ \mathrm{ML}=$ mandibular inclination.

Table 2. Difference between the two groups adjusted for age, gender and body mass index (BMI)

\begin{tabular}{|c|c|c|c|c|c|c|}
\hline Marker & Variable & $\begin{array}{l}\text { Odds } \\
\text { ratio }\end{array}$ & $\begin{array}{c}\text { OR } \\
\text { lower } \mathrm{CL}\end{array}$ & $\begin{array}{c}\text { OR } \\
\text { upper } \mathrm{CL}\end{array}$ & P-value & AUC \\
\hline \multicolumn{7}{|l|}{ Airway dimensions } \\
\hline \multirow{4}{*}{ Volume } & Age & 0.96 & 0.89 & 1.05 & 0.381 & \multirow{4}{*}{0.73} \\
\hline & BMI & 1.1 & 0.92 & 1.32 & 0.301 & \\
\hline & Gender & 1.89 & 0.12 & 29.84 & 0.65 & \\
\hline & Marker & 0.89 & 0.74 & 1.06 & 0.188 & \\
\hline \multirow{4}{*}{ Cross sectional area } & Age & 0.97 & 0.89 & 1.05 & 0.428 & \multirow{4}{*}{0.76} \\
\hline & BMI & 1.07 & 0.88 & 1.3 & 0.5 & \\
\hline & Gender & 1.63 & 0.1 & 26.42 & 0.731 & \\
\hline & Marker & 0.99 & 0.97 & 1 & 0.077 & \\
\hline \multicolumn{7}{|l|}{ Craniofacial morphology } \\
\hline \multirow{4}{*}{ ss-n-pg } & Age & 0.95 & 0.88 & 1.02 & 0.174 & \multirow{4}{*}{0.69} \\
\hline & BMI & 1.16 & 0.98 & 1.37 & 0.091 & \\
\hline & Gender & 3.66 & 0.27 & 50 & 0.331 & \\
\hline & Marker & 1.02 & 0.68 & 1.52 & 0.935 & \\
\hline \multirow{4}{*}{ s-n-ss } & Age & 0.95 & 0.88 & 1.02 & 0.177 & \multirow{4}{*}{0.67} \\
\hline & BMI & 1.16 & 0.98 & 1.37 & 0.085 & \\
\hline & Gender & 4.27 & 0.33 & 56.06 & 0.269 & \\
\hline & Marker & 0.95 & 0.77 & 1.19 & 0.672 & \\
\hline \multirow{4}{*}{ s-n-pg } & Age & 0.95 & 0.88 & 1.02 & 0.171 & \multirow{4}{*}{0.68} \\
\hline & BMI & 1.16 & 0.98 & 1.37 & 0.088 & \\
\hline & Gender & 3.89 & 0.32 & 47.59 & 0.288 & \\
\hline & Marker & 0.96 & 0.78 & 1.17 & 0.685 & \\
\hline \multirow{4}{*}{ NL/ML } & Age & 0.94 & 0.87 & 1.02 & 0.154 & \multirow{4}{*}{0.69} \\
\hline & BMI & 1.15 & 0.97 & 1.37 & 0.108 & \\
\hline & Gender & 3.49 & 0.28 & 44.27 & 0.334 & \\
\hline & Marker & 0.93 & 0.79 & 1.08 & 0.324 & \\
\hline \multirow{4}{*}{ NSL/NL } & Age & 0.95 & 0.88 & 1.02 & 0.167 & \multirow{4}{*}{0.69} \\
\hline & BMI & 1.15 & 0.97 & 1.36 & 0.12 & \\
\hline & Gender & 3.63 & 0.29 & 45.29 & 0.316 & \\
\hline & Marker & 1.13 & 0.88 & 1.45 & 0.33 & \\
\hline \multirow{4}{*}{ NSL/ML } & Age & 0.95 & 0.88 & 1.02 & 0.17 & \multirow{4}{*}{0.69} \\
\hline & BMI & 1.16 & 0.98 & 1.37 & 0.088 & \\
\hline & Gender & 3.72 & 0.3 & 45.67 & 0.304 & \\
\hline & Marker & 0.98 & 0.86 & 1.11 & 0.734 & \\
\hline \multicolumn{7}{|l|}{ Incisal relations } \\
\hline \multirow{4}{*}{ Overjet } & Age & 0.93 & 0.85 & 1.01 & 0.089 & \multirow{4}{*}{0.74} \\
\hline & BMI & 1.18 & 0.99 & 1.4 & 0.067 & \\
\hline & Gender & 4.57 & 0.35 & 59.52 & 0.246 & \\
\hline & Marker & 1.64 & 0.82 & 3.3 & 0.163 & \\
\hline \multirow{4}{*}{ Overbite } & Age & 0.94 & 0.86 & 1.02 & 0.12 & \multirow{4}{*}{0.72} \\
\hline & BMI & 1.18 & 0.99 & 1.4 & 0.072 & \\
\hline & Gender & 4.79 & 0.35 & 65.77 & 0.241 & \\
\hline & Marker & 1.37 & 0.7 & 2.69 & 0.354 & \\
\hline
\end{tabular}

Differences were tested by logistic regression analysis adjusted for age, gender and body mass index (BMI).

$\mathrm{OR}=$ odds ratio; $\mathrm{CL}=$ confidence level; $\mathrm{AUC}=$ area under the curve; ss-n-pg = sagittal jaw relation; s-n-ss = maxillary prognathia; s-n-pg = mandibular prognathia; $\mathrm{NL} / \mathrm{ML}=$ vertical jaw relation; $\mathrm{NSL} / \mathrm{NL}=$ maxillary inclination; $\mathrm{NSL} / \mathrm{ML}=$ mandibular inclination . 
Airway dimensions expressed as volume (P-value 0.044 , OR $=0.85[0.72 ; 1])$ and minimum crosssectional area (P-value 0.019, OR $=0.99 \quad[0.97$; 1]) were statistically significant with hEDS having significantly smaller airway dimensions than controls (Table 1). When the airway volume and minimum cross-sectional area were adjusted for gender, age and BMI, no statistically significant difference was found between the groups (P-value $>0.05$ respectively, Table 2). However, minimum cross-sectional area was almost significant with a P-value of $0.077, \mathrm{OR}=0.99$ $(0.97 ; 1)$ (Table 2).

\section{DISCUSSION}

The aims of the present study were to investigate differences in craniofacial morphology assessed on lateral cephalograms and airway dimensions assessed on CBCTs between a group of patients with hEDS and a group of healthy controls. This has not previously been investigated in hEDS. The hEDS group was not only clinically diagnosed by an experienced specialist but also tested genetically in order to exclude other EDS subtypes, i.e. extremely well-diagnosed [13]. Previous studies have pooled mixed EDS subgroups such as hEDS, clEDS and others $[\underline{9}, \underline{10}]$. The control group in the present study comprised healthy individuals with neutral occlusion and normal craniofacial morphology, which is important for an investigation of the upper airway. Previous studies have found that changes in the upper airway are associated with malocclusion and deviations of the craniofacial morphology such as e.g. a posterior position of the mandible [22-26]. Even though the sample sizes in the hEDS as well as in the control groups in the present study were relatively small, the power analysis showed sufficient power. Still, the sample size may influence the confidence limits of OR.

In the present study, the upper airway dimensions were assessed on CBCT obtained in the natural head position as evaluated by mirror $[16,17]$. For the assessment of the upper airway it is important that the individual is scanned in the natural head position as it has been shown that head posture has an influence on upper airway dimensions $[\underline{19}, \underline{27}]$. Airway dimensions are not static, but influenced by the dynamics of variables such as head posture, state of respiration and mobility of the soft tissues [28-32]. It has been shown on CBCT that an extended head posture is associated with greater airway dimensions and cross sectional area in the level of the os hyoideum, but not with airway volume [19].
In the present study, no statistically significant differences in craniofacial morphology were seen between the two groups. This is in agreement with a previous study, even though that study included a mixed patient group with various subtypes of EDS and a quantitative photographic analysis technique was used to assess the craniofacial morphology [9]. Another study clinically assessed the craniofacial morphology on EDS patients; a morphological analysis of the craniofacial morphology was not included nor was a control group [10]. In that study, the facial structures of the EDS patients were reported to include nasal septum deviation, high arched palatal vault and retrognathia of the jaws [10]. The majority of the EDS patients also had existing complaints of fatigue and poor sleep, so they may have had a craniofacial morphology predisposing to sleep disordered breathing (SDB) and thus may not be representative of the general EDS population.

An explanation for the lack of difference in craniofacial morphology between the hEDS group and the control group in the present study could be that the connective tissue abnormalities particular to hEDS did not have a detectable impact on the craniofacial structures. Furthermore, craniofacial morphology is dependent on many factors including skeletal, soft tissue and function. Hence, craniofacial morphology is a complex entity and most likely more than the sum of the individual parts [27,33-37].

In the present study, the upper airway dimensions were significantly smaller in the hEDS group compared to the control group. When adjusted for age, gender and BMI, the difference was no longer significant, although the minimum cross-sectional area was almost significant. An explanation could be that as there was no difference in craniofacial morphology between the hEDS group and the control group, there was also no difference in upper airway dimensions. Furthermore, the connective tissue abnormality in hEDS may not affect the upper airway dimensions, although the minimum cross-sectional area was almost significant when adjusting for age, gender and BMI. This, however, suggested an impact of hEDS on the upper airway dimensions. It is well known that the upper airways are influenced by age, gender and BMI. Therefore, it is important to adjust for age, gender and BMI in the statistical analysis as was the case in the present study. The size of the upper airway decreases with increasing age in both men and women [38], and sexual dimorphism can be observed in respect to size of the pharynx - men having larger airways than women [39]. Obesity measured as BMI is listed as a predisposition for SDB such as OSA [40]. It was found that body weight, BMI and neck circumference 
was significantly greater in male patients with SDB compared to a normal control group [8]. Furthermore, studies have shown that BMI was related to mandibular advancement device treatment outcome in OSA $[41, \underline{42}]$. Therefore, it may not be surprising that when the results for upper airway volume and minimum cross-sectional area were adjusted for age, gender and BMI, they were no longer statistically significant. However, minimum cross-sectional area was almost significant with a P-value of 0.077 . This may suggest an impact of hEDS on the upper airway dimensions and that patients with hEDS may be more susceptible to obstruction of the upper airway.

\section{CONCLUSIONS}

Craniofacial morphology and airway dimensions of patients with hypermobile Ehlers-Danlos syndrome were comparable to those in healthy controls when adjusted for age, gender and body mass index with a tendency towards a smaller minimum crosssectional area in the hypermobile Ehlers-Danlos syndrome group. The results of the present study may prove valuable in the understanding of the effect of hypermobile Ehlers-Danlos syndrome on craniofacial morphology and the upper airway and may indicate a tendency towards an impact of the underlying connective tissue disorder on the upper airway dimensions.

\section{ACKNOWLEDGMENTS AND DISCLOSURE STATEMENTS}

Palle Svanholt (Section of Orthodontics, Department of Odontology, University of Copenhagen, Denmark), specialist in orthodontics is thanked for guidance in performing the airway analysis. Ib Jarle Christensen (Department of Gastroenterology, Hvidovre Hospital, Denmark), senior scientist, MSc is acknowledged for the statistical analysis. Maria Kvetny (Department of Odontology, University of Copenhagen, Denmark), MA, is acknowledged for linguistic support. For financial support the Danish Dental Association, "Grosserer L. F. Foghts" Fond, The Ehlers Danlos Society Microgrant, USA and the Danish "EhlersDanlos forening" is thanked. The authors report no conflicts of interest related to this study.

\section{REFERENCES}

1. Malfait F, Francomano C, Byers P, Belmont J, Berglund B, Black J, Bloom L, Bowen JM, Brady AF, Burrows NP, Castori M, Cohen H, Colombi M, Demirdas S, De Backer J, De Paepe A, Fournel-Gigleux S, Frank M, Ghali N, Giunta C, Grahame R, Hakim A, Jeunemaitre X, Johnson D, Juul-Kristensen B, Kapferer-Seebacher I, Kazkaz H, Kosho T, Lavallee ME, Levy H, Mendoza-Londono R, Pepin M, Pope FM, Reinstein E, Robert L, Rohrbach M, Sanders L, Sobey GJ, Van Damme T, Vandersteen A, van Mourik C, Voermans N, Wheeldon N, Zschocke J, Tinkle B. The 2017 international classification of the Ehlers-Danlos syndromes. Am J Med Genet C Semin Med Genet. 2017 Mar;175(1):8-26. [Medline: 28306229] [doi: 10.1002/ajmg.c.31552]

2. Morgan AW, Pearson SB, Davies S, Gooi HC, Bird HA. Asthma and airways collapse in two heritable disorders of connective tissue. Ann Rheum Dis. 2007 Oct;66(10):1369-73. [Medline: 17412739] [PMC free article: 1994284] [doi: 10.1136/ard.2006.062224]

3. Kulas Søborg ML, Leganger J, Quitzau Mortensen L, Rosenberg J, Burcharth J. Establishment and baseline characteristics of a nationwide Danish cohort of patients with Ehlers-Danlos syndrome. Rheumatology (Oxford). 2017 May 1;56(5): 763-767. [Medline: 28077691] [doi: 10.1093/rheumatology/kew478]

4. Forghani I. Updates in Clinical and Genetics Aspects of Hypermobile Ehlers Danlos Syndrome. Balkan Med J. 2019 Jan 1;36(1):12-16. [Medline: 30063214] [PMC free article: 6335943] [doi: 10.4274/balkanmedj.2018.1113]

5. Marieb E, Hoehn K. Human Anatomy and Physiology. 11th ed. Harlow (UK): Pearson Education Inc.; 2018.

6. Hagberg CA. Benumof and Hagberg's Airway Management. 3rd Edition. Philadelhpia (PA): Elsevier/Saunders; 2012. p. 1-1141. [doi: 10.1016/B978-1-4377-2764-7.00057-9]

7. Standring, S. Gray's anatomy: The anatomical basis of clinical practice. 41st edition. Philadelphia: Elsevier; 2016. p. 1584.

8. Watanabe $\mathrm{T}$, Isono $\mathrm{S}$, Tanaka $\mathrm{A}$, Tanzawa $\mathrm{H}$, Nishino $\mathrm{T}$. Contribution of body habitus and craniofacial characteristics to segmental closing pressures of the passive pharynx in patients with sleep-disordered breathing. Am J Respir Crit Care Med. 2002 Jan 15;165(2):260-5. [Medline: 11790665] [doi: 10.1164/ajrccm. 165.2.2009032]

9. Gaisl T, Giunta C, Bratton DJ, Sutherland K, Schlatzer C, Sievi N, Franzen D, Cistulli PA, Rohrbach M, Kohler M. Obstructive sleep apnoea and quality of life in Ehlers-Danlos syndrome: a parallel cohort study. Thorax. 2017 Aug;72(8):729-735. [Medline: 28073822] [doi: 10.1136/thoraxjnl-2016-209560]

10. Guilleminault C, Primeau M, Chiu HY, Yuen KM, Leger D, Metlaine A. Sleep-disordered breathing in EhlersDanlos syndrome: a genetic model of OSA. Chest. 2013 Nov;144(5):1503-1511. [Medline: 23929538] [doi: 10.1378/chest.13-0174] 
11. Sedky K, Gaisl T, Bennett DS. Prevalence of Obstructive Sleep Apnea in Joint Hypermobility Syndrome: A Systematic Review and Meta-Analysis. J Clin Sleep Med. 2019 Feb 15;15(2):293-299. [Medline: 30736885] [PMC free article: 6374081] [doi: 10.5664/jcsm.7636]

12. Chen H, Aarab G, de Ruiter MH, de Lange J, Lobbezoo F, van der Stelt PF. Three-dimensional imaging of the upper airway anatomy in obstructive sleep apnea: a systematic review. Sleep Med. 2016 May;21:19-27. [Medline: 27448467] [doi: 10.1016/j.sleep.2016.01.022]

13. Honoré MB, Lauridsen EF, Sonnesen L. Oro-dental characteristics in patients with hypermobile Ehlers-Danlos Syndrome compared to a healthy control group. J Oral Rehabil. 2019 Nov;46(11):1055-1064. [Medline: 31206735] [doi: $10.1111 /$ joor.12838]

14. Beighton P, De Paepe A, Steinmann B, Tsipouras P, Wenstrup RJ. Ehlers-Danlos syndromes: revised nosology, Villefranche, 1997. Ehlers-Danlos National Foundation (USA) and Ehlers-Danlos Support Group (UK). Am J Med Genet. 1998 Apr 28;77(1):31-7. [Medline: 31206735] [doi: 10.1002/(SICI)1096-8628(19980428)77:13.0.CO;2-O]

15. Björk A. The face in profile: an anthropological X-ray investigation on Swedish children and conscripts. Lund; Berlingska Boktryckeriet. Svenska Tandlakara Tidskrift, 1947;40(5B):124-68.

16. Siersbaek-Nielsen S, Solow B. Intra- and interexaminer variability in head posture recorded by dental auxiliaries. Am J Orthod. 1982 Jul;82(1):50-7. [Medline: 6961777] [doi: 10.1016/0002-9416(82)90546-2]

17. Solow B, Tallgren A. Natural head position in standing subjects. Acta Odontol Scand. 1971 Nov;29(5):591-607. [Medline: 5290983] [doi: 10.3109/00016357109026337]

18. Anandarajah S, Abdalla Y, Dudhia R, Sonnesen L. Proposal of new upper airway margins in children assessed by CBCT. Dentomaxillofac Radiol. 2015;44(7):20140438. [Medline: 25806863] [PMC free article: 4628407] [doi: $10.1259 / \mathrm{dmfr} .20140438$ ]

19. Sonnesen L, Petersson A, Berg S, Svanholt P. Pharyngeal Airway Dimensions and Head Posture in Obstructive Sleep Apnea Patients with and without Morphological Deviations in the Upper Cervical Spine. J Oral Maxillofac Res. 2017 Sep 30;8(3):e4. [Medline: 29142656] [PMC free article: 5676314] [doi: 10.5037/jomr.2017.8304]

20. Dahlberg, G. Statistical Methods for Medical and Biological Students. Br Med J. 1940 Sep 14;2(4158):358-9. [PMC free article: 2179091] [doi: 10.1136/bmj.2.4158.358-b]

21. Houston WJ. The analysis of errors in orthodontic measurements. Am J Orthod. 1983 May;83(5):382-90. [Medline: 6573846] [doi: 10.1016/0002-9416(83)90322-6]

22. Abdalla Y, Brown L, Sonnesen L. Effects of a fixed functional appliance on upper airway volume: A 3-dimensional cone-beam computed tomography study. Am J Orthod Dentofacial Orthop. 2020 Jul;158(1):40-49. [Medline: $\underline{32389570}$ ] [doi: 10.1016/j.ajodo.2019.07.013]

23. Alves M Jr, Franzotti ES, Baratieri C, Nunes LK, Nojima LI, Ruellas AC. Evaluation of pharyngeal airway space amongst different skeletal patterns. Int J Oral Maxillofac Surg. 2012 Jul;41(7):814-9. [Medline: 22365893] [doi: 10.1016/j.ijom.2012.01.015]

24. Anandarajah S, Dudhia R, Sandham A, Sonnesen L. Risk factors for small pharyngeal airway dimensions in preorthodontic children: A three-dimensional study. Angle Orthod. 2017 Jan;87(1):138-146. [Medline: 27304232] [doi: $10.2319 / 012616-71.1]$

25. Bollhalder J, Hänggi MP, Schätzle M, Markic G, Roos M, Peltomäki TA. Dentofacial and upper airway characteristics of mild and severe class II division 1 subjects. Eur J Orthod. 2013 Aug;35(4):447-53. [Medline: 22427406] [doi: 10.1093/ejo/cjs010]

26. El H, Palomo JM. An airway study of different maxillary and mandibular sagittal positions. Eur J Orthod. 2013 Apr;35(2):262-70. [Medline: 22045695] [doi: 10.1093/ejo/cjr114]

27. Solow B, Siersbaek-Nielsen S, Greve E. Airway adequacy, head posture, and craniofacial morphology. Am J Orthod. 1984 Sep;86(3):214-23. [Medline: 6591801] [doi: 10.1016/0002-9416(84)90373-7]

28. Guijarro-Martínez R, Swennen GR. Cone-beam computerized tomography imaging and analysis of the upper airway: a systematic review of the literature. Int J Oral Maxillofac Surg. 2011 Nov;40(11):1227-37. [Medline: 21764260] [doi: 10.1016/j.ijom.2011.06.017]

29. Hellsing E. Changes in the pharyngeal airway in relation to extension of the head. Eur J Orthod. 1989 Nov;11(4):359-65. [Medline: 2591483] [doi: 10.1093/oxfordjournals.ejo.a036007]

30. Muto T, Yamazaki A, Takeda S, Kawakami J, Tsuji Y, Shibata T, Mizoguchi I. Relationship between the pharyngeal airway space and craniofacial morphology, taking into account head posture. Int J Oral Maxillofac Surg. 2006 Feb;35(2):132-6. [Medline: 15961280] [doi: 10.1016/j.ijom.2005.04.022]

31. Schwab RJ, Gefter WB, Hoffman EA, Gupta KB, Pack AI. Dynamic upper airway imaging during awake respiration in normal subjects and patients with sleep disordered breathing. Am Rev Respir Dis. 1993 Nov;148(5):1385-400. [Medline: 8239180] [doi: 10.1164/ajrccm/148.5.1385]

32. Solow B, Skov S, Ovesen J, Norup PW, Wildschiødtz G. Airway dimensions and head posture in obstructive sleep apnoea. Eur J Orthod. 1996 Dec;18(6):571-9. [Medline: 9009421] [doi: 10.1093/ejo/18.6.571]

33. Linder-Aronson S. Adenoids. Their effect on mode of breathing and nasal airflow and their relationship to characteristics of the facial skeleton and the denition. A biometric, rhino-manometric and cephalometro-radiographic study on children with and without adenoids. Acta Otolaryngol Suppl. 1970;265:1-132. [Medline: 5272140] 
34. McNamara JA. Influence of respiratory pattern on craniofacial growth. Angle Orthod. 1981 Oct;51(4):269-300. [Medline: 6947703 ]

35. Peltomäki T. The effect of mode of breathing on craniofacial growth--revisited. Eur J Orthod. 2007 Oct;29(5):426-9. [Medline: 17804427] [doi: 10.1093/ejo/cjm055]

36. Vargervik K, Harvold EP. Experiments on the interaction between orofacial function and morphology. Ear Nose Throat J. 1987 May;66(5):201-8. [Medline: 3107964$]$

37. Vargervik K, Miller AJ, Chierici G, Harvold E, Tomer BS. Morphologic response to changes in neuromuscular patterns experimentally induced by altered modes of respiration. Am J Orthod. 1984 Feb;85(2):115-24. [Medline: 6594052] [doi: 10.1016/0002-9416(84)90003-4]

38. Martin SE, Mathur R, Marshall I, Douglas NJ. The effect of age, sex, obesity and posture on upper airway size. Eur Respir J. 1997 Sep;10(9):2087-90. [Medline: 9311508] [doi: 10.1183/09031936.97.10092087]

39. Brooks LJ, Strohl KP. Size and mechanical properties of the pharynx in healthy men and women. Am Rev Respir Dis. 1992 Dec;146(6):1394-7. [Medline: 1456554] [doi: 10.1164/ajrccm/146.6.1394]

40. Malhotra A, White DP. Obstructive sleep apnoea. Lancet. 2002 Jul 20;360(9328):237-45. [Medline: 12133673] [doi: 10.1016/S0140-6736(02)09464-3]

41. Knappe SW, Sonnesen L. Mandibular positioning techniques to improve sleep quality in patients with obstructive sleep apnea: current perspectives. Nat Sci Sleep. 2018 Feb 2;10:65-72. [Medline: 29440942] [PMC free article: 5800493] [doi: $10.2147 /$ NSS.S135760]

42. Svanholt P, Petri N, Wildschiødtz G, Sonnesen L. Influence of craniofacial and upper spine morphology on mandibular advancement device treatment outcome in patients with obstructive sleep apnoea: a pilot study. Eur J Orthod. 2015 Aug;37(4):391-7. [Medline: 25351571] [doi: 10.1093/ejo/cju064]

\section{To cite this article:}

Sonnesen L, Pawlik T, Fejerskov Lauridsen E.

Craniofacial Morphology and Upper Airway Dimensions in Patients with Hypermobile Ehlers-Danlos Syndrome Compared to Healthy Controls

J Oral Maxillofac Res 2021;12(2):e5

URL: http://www.ejomr.org/JOMR/archives/2021/2/e5/v12n2e5.pdf

doi: $10.5037 /$ jomr.2021.12205

Copyright (C) Sonnesen L, Pawlik T, Fejerskov Lauridsen E. Published in the JOURNAL OF ORAL \& MAXILLOFACIAL RESEARCH (http://www.ejomr.org), 30 June 2021.

This is an open-access article, first published in the JOURNAL OF ORAL \& MAXILLOFACIAL RESEARCH, distributed under the terms of the Creative Commons Attribution-Noncommercial-No Derivative Works 3.0 Unported License, which permits unrestricted non-commercial use, distribution, and reproduction in any medium, provided the original work and is properly cited. The copyright, license information and link to the original publication on (http://www.ejomr.org) must be included. 